\title{
Enhancement of antitumor effect using dendritic cells activated with natural killer cells in the presence of Toll-like receptor agonist
}

\author{
Thanh Nhan Nguyen Pham ${ }^{1,2,6}$, Cheol Yi Hong ${ }^{1}$, \\ Jung-Joon Min ${ }^{3,6}$, Joon-Haeng Rhee ${ }^{4,6}$, \\ Truc-Anh Thi Nguyen ${ }^{1,2,6}$, Byoung Chul Park ${ }^{7}$, \\ Deok-Hwan Yang ${ }^{1,2}$, Young-Kyu Park ${ }^{1,5}$, \\ Hyeong-Rok Kim ${ }^{5,6}$, lk-Joo Chung ${ }^{1,2,6}$, \\ Hyeoung-Joon $\mathrm{Kim}^{2}$ and Je-Jung Lee ${ }^{1,2,6,8}$ \\ ${ }^{1}$ Research Center for Cancer Immunotherapy \\ Chonnam National University Hwasun Hospital \\ Jeonnam 519-809, Korea \\ ${ }^{2}$ Department of Hematology-Oncology \\ ${ }^{3}$ Department of Nuclear Medicine \\ ${ }^{4}$ Department of Microbiology \\ ${ }^{5}$ Department of Surgery \\ Chonnam National University Medical School \\ Gwangju 501-757, Korea \\ ${ }^{6}$ The Brain Korea 21 Project \\ Center for Biomedical Human Resources at \\ Chonnam National University \\ Gwangju 500-757, Korea \\ ${ }^{7}$ Korea Research Institute of Bioscience and Biotechnology (KRIBB), \\ Daejeon 305-806, Korea \\ ${ }^{8}$ Corresponding author: Tel, 82-61-379-7638; \\ Fax, 82-61-379-7628; E-mail, drjejung @ chonnam.ac.kr \\ DOI 10.3858/emm.2010.42.6.042
}

Accepted 6 April 2010

Available Online 13 April 2010

Abbreviations: BM, bone marrow; CD40L, CD40 ligand; CTL, cytotoxic T lymphocyte; DC, dendritic cell; MACS, magnetic activated cell sorter; MFI, mean fluorescence intensity; MLR, mixed lymphocyte reaction; NK cell, natural killer cell; ROI, region of interest; STAT, signal transducers and activators of transcription; TLR, Toll-like receptor

\begin{abstract}
Dendritic cells (DCs) play a role in natural killer (NK) cell activation, while NK cells are also able to activate and mature DCs. Toll-like receptors (TLRs) on the surface of DCs and NK cells induce the maturation and activation of these cells when engaged with their cognate ligand. We investigated to generate potent DCs by maturation with NK cells in the presence of TLR agonist in vitro and tested the efficacy of these $\mathrm{DC}$ vaccinations
\end{abstract}

in mouse colon cancer model. The optimal ratios of DCs versus NK cells were 1:1 to 1:2. Immature DCs were mature with NK cells in the presence of lipopolysaccharide, which is TLR4 agonist, and further addition of IL-2 induced phenotypically and functionally mature bone marrow-derived DCs. These potent DCs exhibited not only high expression of several costimulatory molecules and high production of IL-12p40 and IL-12p70, but also high allogeneic T cells stimulatory capacity, and the induction of the high activities to generate tumor-specific CTLs. Consistently, vaccination with these DCs efficiently inhibited CT-26 tumor growth in mouse colon cancer model when compared to other vaccination strategies. Interestingly, combination therapy of these DC-based vaccines and with low-dose cyclophosphamide showed dramatic inhibition effects of tumor growth. These results suggest that the DCs maturated with NK cells in the presence of TLR agonist are potent inducer of antitumor immune responses in mouse model and may provide a new source of DC-based vaccines for the development of immunotherapy against colon cancer.

Keywords: cancer vaccines; chemotherapy; dendritic cells; immunotherapy; natural killer cells; Tolllike receptor 4

\section{Introduction}

Dendritic cells (DCs)-based vaccines continue to be considered an attractive tool for cancer immunotherapy (Ridgway, 2003; Cranmer et al., 2004). Toll-like receptors (TLRs) are pattern-recognition receptors that trigger innate immune responses as well as the adaptive immune system by the induction of DC recruitment and maturation (Akira and Hemmi, 2003; Schuurhuis et al., 2006). Recently, TLRs have been implicated in pathogen recognition by NK cells. Human and murine NK cells constitutively express functional TLRs, produce IFN- $\gamma$, and induce cytotoxic activities in response to TLR ligands (Chalifour et al., 2004; Schmidt et al., 2004; Sivori et al., 2004; Lauzon et al., 2006). In addition, although NK cells can be directly activated by TLRs, monocytes play an essential role in the activation of effector functions 
A

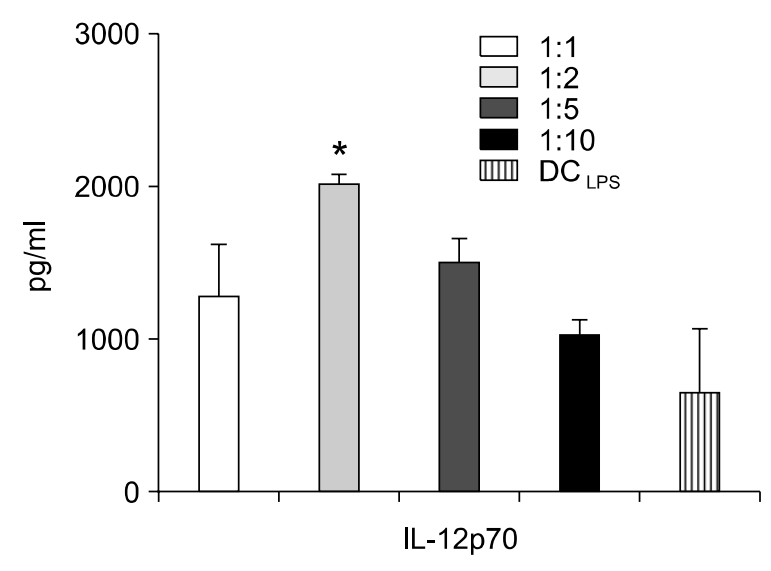

B

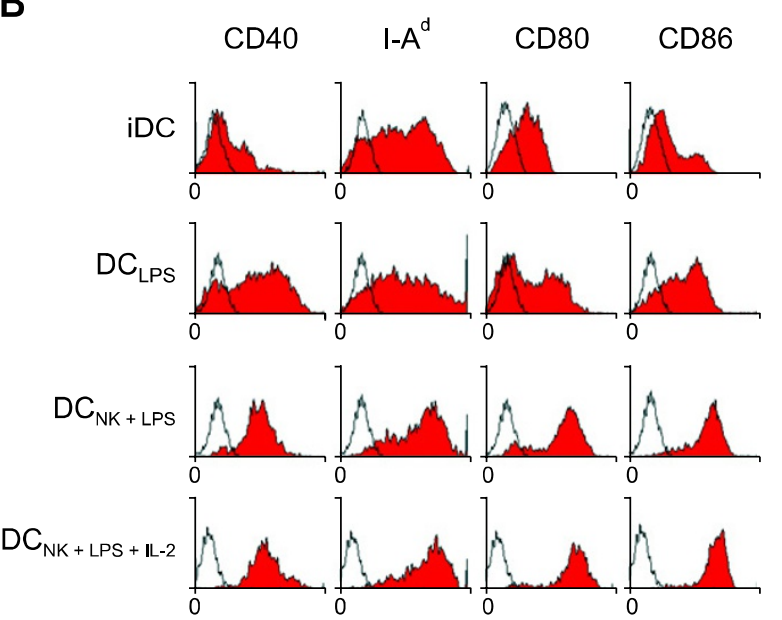

C
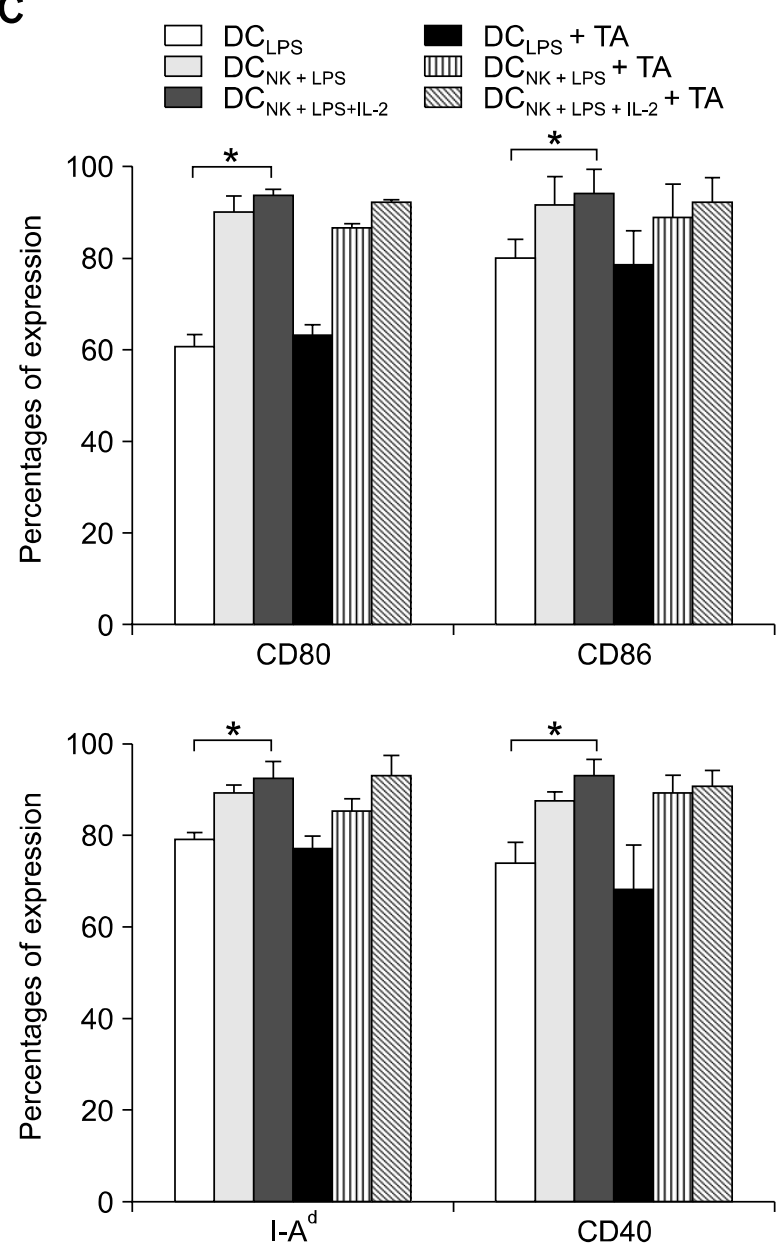

Figure 1. DC characteristics in maturation with NK cells. (A) Optimal ratio of DC versus NK cell. Immature DCs (iDCs) were co-cultured with NK cells at various ratios from 1:1 to 1:10. Culture supernatants were analyzed for IL-12p70 production. DCs maturated with NK cells at a ratio of 1:2 produced higher level of IL-12p70 than other ratios $\left({ }^{*}, P<0.05\right)$. The data from a representative of three independent experiments are shown. (B) Comparison of phenotype of mature DCs. iDCs were co-cultured with NK cells at ratio of 1:2 in the presence of LPS and/or IL-2. The expressions of I-A, CD40, CD80 and $\mathrm{CD} 86$ were analyzed by flow cytometry. $\mathrm{DC}_{\mathrm{NK}+\mathrm{LPS}+\mathrm{LL}-2}$ were expressed the highest levels of these molecules. Shown are representative histograms demonstrating the expression of markers (shaded) compared to isotype controls (black line). (C) Bar graphs showed the mean \% expression (+SD) from five independent experiments. " $P<0.05$ compared to $D C_{\text {LPS. }}$. There were no significant effects of tumor antigens (TA) on the expressions of surface molecules on DCs.

(Hart et al., 2005).

TLR-induced stimulation of both DCs and NK cells plays a crucial role in inducing NK cells to activate immature DCs (iDCs) and to facilitate their maturation. NK-DC interactions have been shown to be important for optimal immune cell expansion and activation during viral infection in vivo (Andrews et al., 2003). In vitro-interaction between NK cells and maturing DCs results in activation and cytokine production of both cell types (Osada et al., 2001; Ferlazzo et al., 2002; Gerosa et al., 2002; Piccioli et al., 2002). The enhancement of IFN- $\gamma$ production, cytotoxicity, CD69 expression and proliferation of NK cells in vitro by activated DCs has been reported (Osada et al., 2001; Ferlazzo et al., 2002; Gerosa et al., 2002; Moretta, 2002; Piccioli et al., 2002). Reversely, the DCs can be activated or matured by interactions with NK cells, resulted in increase cytokine production, co-stimulatory molecules expression or ability to stimulate T-cell. NK cells might profoundly influence DC function by lysis immature DCs and secrete cytokines such as IFN- $\gamma$, TNF- $\alpha$, and GM-CSF, promoting the maturation of DCs (Ferlazzo et al., 2002; Moretta, 2002; Cooper et al., 2004). The activation of NK cells by IL-2 are potent 
A

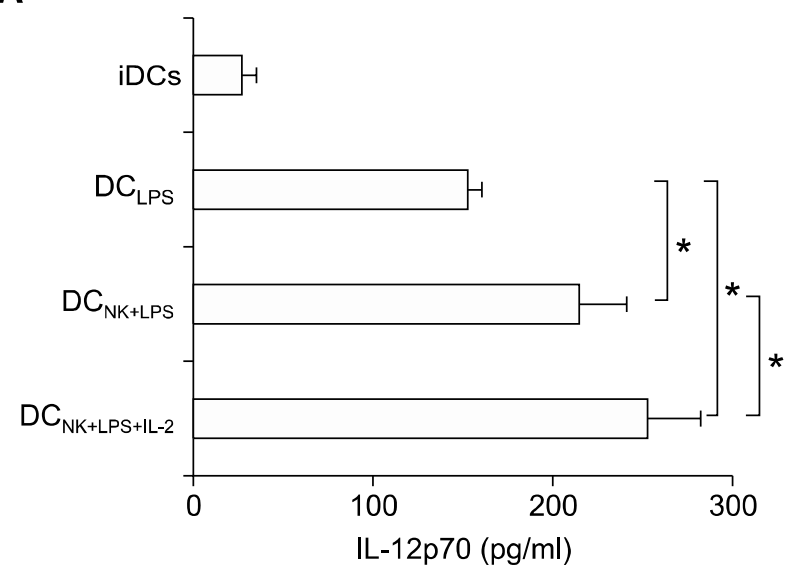

C

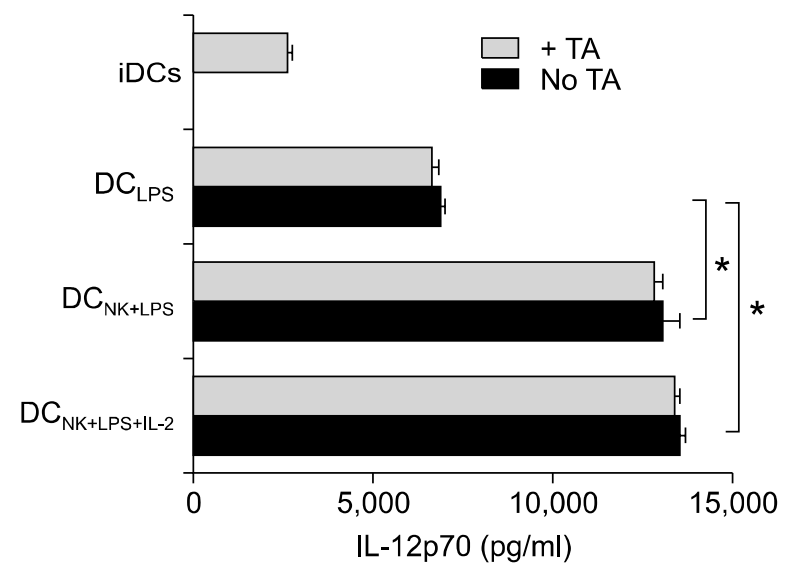

B

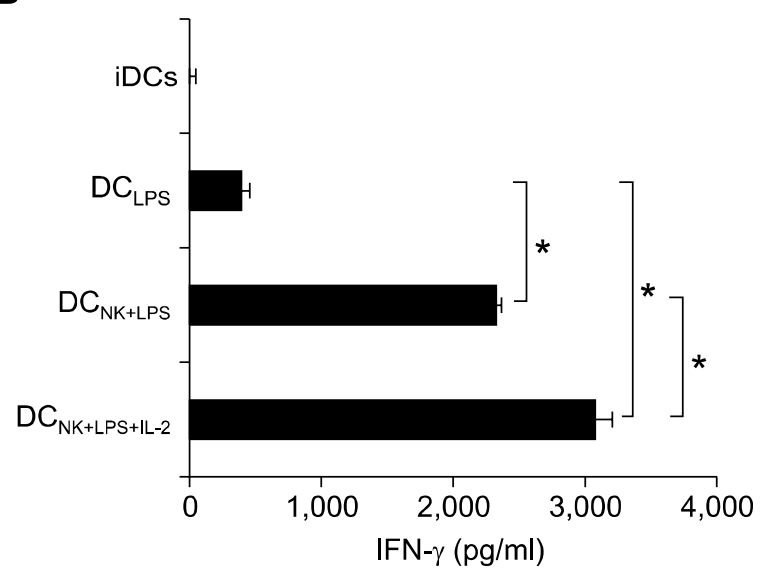

D

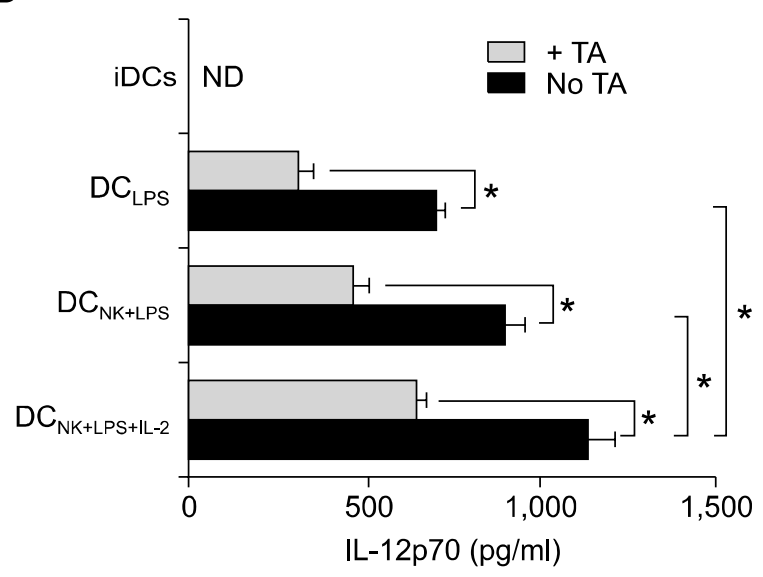

Figure 2. Cytokine production of DCs. iDCs were co-cultured with NK cells at ratio of $1: 2$ in the presence of indicated stimulation reagents. (A) All DCs further stimulated with CD40L-transfected J558 cells for IL-12p70 production. DC $\mathrm{NK}_{\mathrm{NLPS}+\mathrm{LL}-2}$ showed significantly higher production of IL-12p70 than other

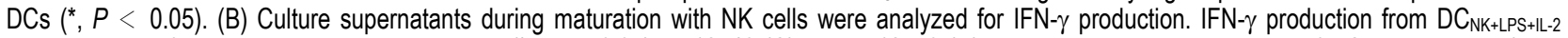
group was significantly higher than other groups ( $\left.{ }^{*}, P<0.05\right)$. IL-12p40 (C) and IL-12p70 (D) productions during maturation of DCs loaded with (gray bar) or without (black bar) tumor antigens (TA). Loading of tumor antigens onto DCs suppressed the production of IL-12p70 $\left({ }^{*}, P<0.05\right)$, but not IL-12p40. The differences in suppression were not eliminated between the $D C_{N K+L P S+I L-2}$ group and other groups $\left.{ }^{*}, P<0.05\right)$. The data are shown as the mean $(\mathrm{pg} / \mathrm{ml})( \pm \mathrm{S} . \mathrm{D})$ of triplicate cultures from two representative data sets from four independent experiments.

DC activators, both alone or in synergy with inflammatory stimuli, such as lipopolysaccharide (LPS) (Gerosa et al., 2002; Piccioli et al., 2002). Activated NK cells could boost ongoing adaptive responses by producing IFN- $\gamma$, which promotes the Th1 polarization of antigen-specific $\mathrm{T}$ cells. In addition, NK cells may boost the activation and the T-cell stimulatory capacity of mature DCs. Activation of human DCs by NK cells results in the differentiation to a DC capable of inducing a more efficient Th1-type and CTL response (Mailliard et al., 2003; Kalinski et al., 2005).

Recent studies have shown that chemotherapeutic agents increase the efficacy of active or adoptive antitumor immunotherapies through bene- ficial immunomodulatory effects (Ghiringhelli et al., 2004; Mihalyo et al., 2004). Among them, cyclophosphamide (CPM) may eliminate the activities of tumor-induced suppressor T cells in tumor-bearing hosts (North, 1982) and induce the production of immunostimulatory cytokines, such as type I interferon (Proietti et al., 1998). In addition, low-dose cyclophosphamide treatment has been shown to down-regulate suppressor $\mathrm{T}$ cells and to decrease the production of TGF- $\beta$ and IL-10 while inducing a Th2/Th1 shift in the cytokine profile (Berd et al., 1984; Matar et al., 2000, 2002).

The purpose of this study was to identify a new source of $D C$ vaccines against colon cancer. To investigate the role of NK cells in DC maturation 
A

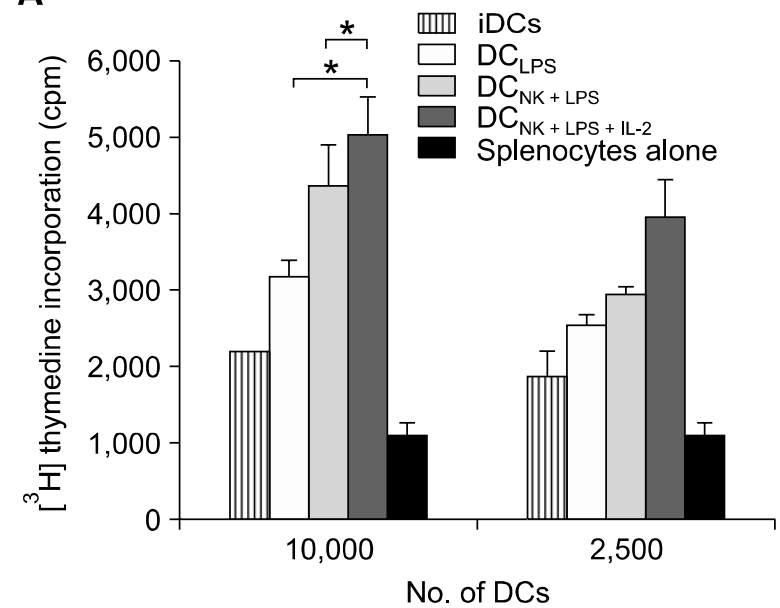

B

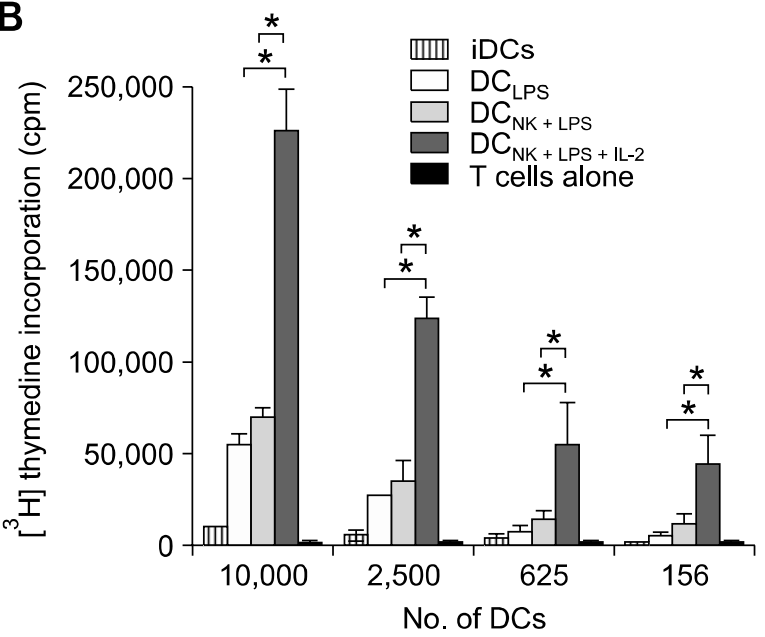

Figure 3. The allostimulatory capacity of DCs. Splenocytes (A) or $\mathrm{CD} 0^{+} \mathrm{T}$ cells (B) $(50,000$ cells/well) obtained from allogeneic mice were stimulated with graded doses of irradiated DCs for 5 days, and $\left.{ }^{3} \mathrm{H}\right]$-methylthymidine was added $18 \mathrm{~h}$ before measurement of proliferative response. The stimulatory capacity of $D C_{N K+L P S+L L-2}$ was significantly higher in splenocytes and T cells than other DCs $\left({ }^{*}, P<0.05\right)$. Data shown are the mean cpm $( \pm S . D)$ of triplicate cultures from three independent experiments.

when engaged with TLR agonists, we used the nature of DC-NK cell interaction to induce the function of DCs to enhance their anti-tumor responses. Here we demonstrate that functionally potent DCs can be generated by co-culture with NK cells as helper cells in the presence of TLR agonist, and exert strong anti-tumor activity as a cancer vaccine.

\section{Results}

\section{NK cells enhance maturation of DCs in the presence of TLR agonist}

In the interaction between DCs and NK cells, the ratio of DCs and NK cells is important (Gerosa et al., 2002; Piccioli et al., 2002). To determine the optimal ratio of DCs versus NK cells, we co-cultured iDCs with NK cells at various ratios $(1: 1,1: 2,1: 5$, and $1: 10)$. The levels of CD40, CD80, CD86 and I-A ${ }^{\mathrm{d}}$ expression on mature DCs were markedly increased at the ratios of $1: 1$ to $1: 2$, and IL-12p70 was significantly increased at the ratio of 1:2 compared to the other ratios (Figure $1 \mathrm{~A}$ and Supplemental data Figure S1). There were no significant differences in the production of IL-12p40 and $\mathrm{IL}-10$ among all ratios (data not shown). Therefore, we chose the ratio of $1: 2$ for the subsequent experiments.

BM cells harvested on day 7 were typically and phenotypically differentiated to iDCs; they expressed intermediate levels of $\mathrm{I}^{\mathrm{d}} \mathrm{A}^{\mathrm{d}}, \mathrm{CD} 80$ and CD86 and low levels of CD40. Mature DCs were generated by co-culture with the NK cells in the presence of the TLR4 agonist ( $D C_{N K+L P S}$ ), and markedly increased the expression of $I-A^{d}, C D 80$, CD86 and CD40 (Figure 1B). The addition of IL-2 to $D C_{N K+L P S}\left(D C_{N K+L P S+I L-2}\right)$ further increased the expression of these surface molecules. This pattern of the surface molecules indicated that mature BM-derived DCs were generated by co-cultured with NK cells in the presence of TLR agonist. Tumor antigen-pulsed DCs also showed the typical phenotype of mature DCs, suggesting that the antigen-loading strategy did not affect the maturation of DCs (data not shown). The comparison of five independent experiments showed the highest levels of surface marker expression on $D C_{N K+L P S+I L-2}$ (Figure 1C).

\section{DCs interaction with NK cells profoundly enhance cytokine production}

To determine whether co-culture of iDCs with NK cells in the presence of TLR agonist could enhance cytokine production and Th1-promotion, we measured the levels of IFN- $\gamma$, IL-12p40 and IL-12p70 production during DC maturation and after subsequent stimulation of the DCs with CD40L-transfected $J 558$ cells. Co-culture of iDCs with NK cells in the presence of TLR agonist ( $D_{\mathrm{NK}+\mathrm{LPS}}$ ) profoundly enhanced the ability of maturing DCs to produce IL-12p40 and IL-12p70 during maturation, as well as IL-12p70 in response to subsequent CD40L stimulation as compared to LPS-primed DCs (DC $C_{L P S}$ ) (Figure $2 A$ and Supplemental data 
A

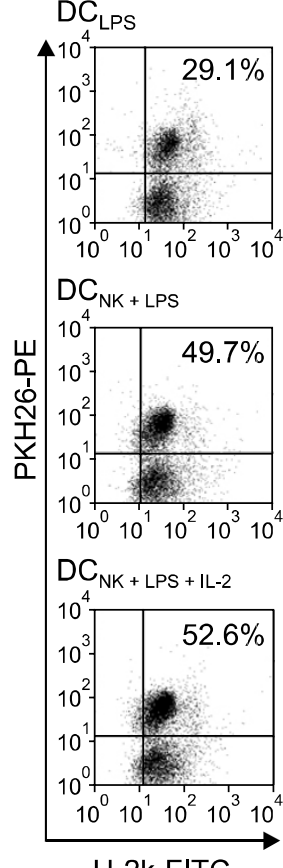

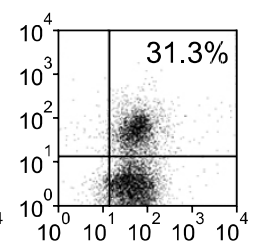
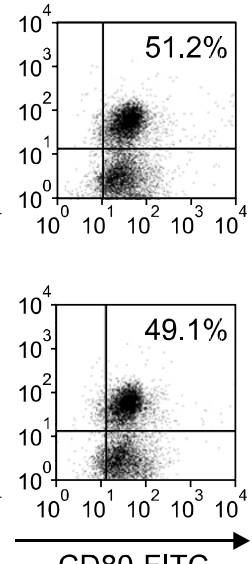

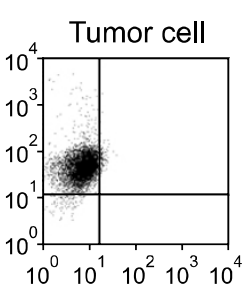

B
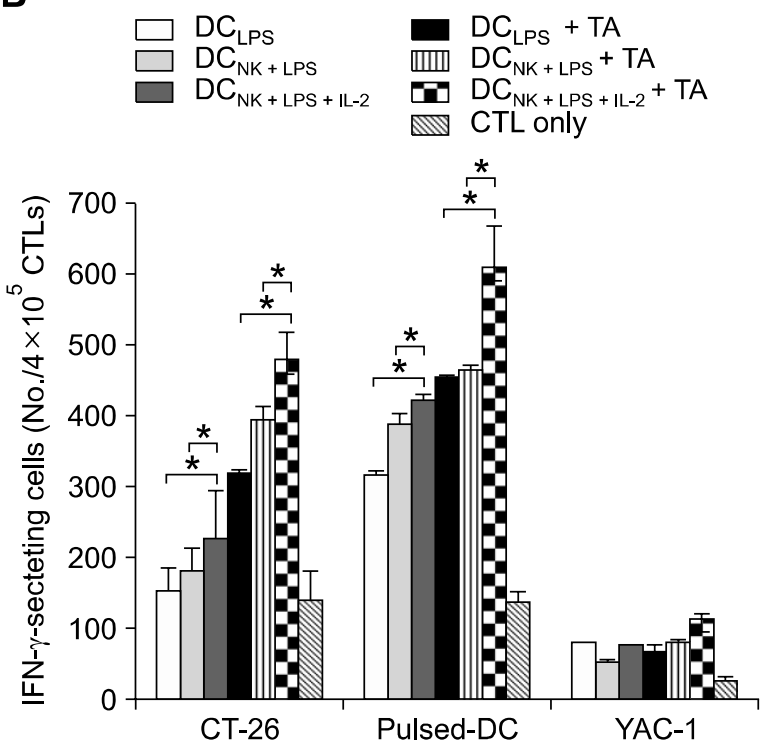

CD11C-FITC

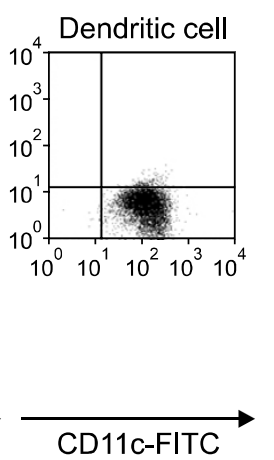

Figure 4. Tumor antigen uptake of DCs and tumor specific IFN- $\gamma$ secreting CTLs. (A) DCs were loaded with PKH26-labeled UVB-irradiated CT26 cells at a ratio of 2:1. CD11 $\mathrm{c}^{+}$mature-DCs, identified by $\mathrm{H}-2 \mathrm{k}$ or $\mathrm{CD} 80$ expression, were analyzed for the uptake of PKH26 labeled tumor cells. $\mathrm{DC} \mathrm{CKK}_{\mathrm{N}+\mathrm{LS}}$ and $D C_{N K+L P S+L-2}$ showed more efficiently take up irradiated tumor cells compared to DCLPS. The data from a single representative experiment are shown. (B) Autologous T cells were stimulated with irradiated-pulsed or unpulsed DCs. The CTLs were co-cultured with target cells (CT26 cells and

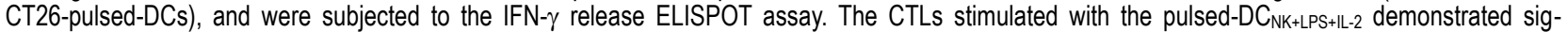
nificantly higher IFN- $\gamma$-secreting cells against target cells than other CTLs $\left.{ }^{*}, P<0.05\right)$. A few IFN- $\gamma$ secreting cells were produced when YAC-1 was used as target cells. The data are shown as the mean numbers of IFN- $\gamma$-secreting cells ( \pm S.D) of triplicate culture from a representative data from three independent experiments.

Figure S2). Moreover, the productions of these cytokines were significant increased in the presence of the NK cell-activating cytokine, IL-2 (Figure 2A and Supplemental Data Figure S2). Reciprocally, NK cells co-cultured with iDCs in the presence of TLR agonist and IL-2 (DC NK $+L P S+L L-2)$ showed significantly increased production of IFN- $\gamma$ compared to the other DCs (Figure 2B). These results were compatible with the hypothesis that DCs play a role in the activation of NK cells, while NK cells are also involved in the activation and maturation of DCs.

The ingestion of dying cells by APCs can markedly influence the enhancement or suppression of immune responses (Savill et al., 2002). To evaluate the affect of apoptotic tumor cells on the differentially mature DCs, we measured the levels of IL-12p40 and IL-12p70 production in tumor loaded DCs. Consistent with the immuno-suppressed status of tumor cell-pulsed DCs resulted in decrease the production of Th-1-polarizing cytokines (Savill et al., 2002), the level of IL-12p70, but not IL-12p40, were significantly suppressed as compared to unpulsed DCs (Figures 2C and 2D).

\section{Maturation of DCs with NK cells in the presence of TLR agonist enhance the T cell stimulatory capacity}

To evaluate the ability of mouse DC maturation with NK cells in the presence of TLR agonist to stimulate T cells, we performed an allogeneic MLR assay with both splenocytes and T cells. $D C_{N K+L P S}$ showed a potent allogeneic $T$ cell stimulatory capacity in a dose-dependent manner based on the increasing number of DCs. The addition of IL-2 during the maturation of DCs with NK cells and TLR agonist ( $\left.D C_{N K+L P S+L L-2}\right)$ further augmented the MLR activity of these DCs (Figures $3 A$ and $3 B$ ).

\section{Maturation of DCs with NK cells in the presence of TLR agonist enhanced the efficiency of tumor antigen uptake and their ability to generate tumor-specific CTLs}

To examine the ability to take up tumor antigens, we compared the level of PKH26-labeled-irradiated CT26 cell which can be taken up by DCs. DC $C_{N K+L P S}$ showed a more efficient uptake of UV-irradiated tumor cells as compared to the DCs that were 
A

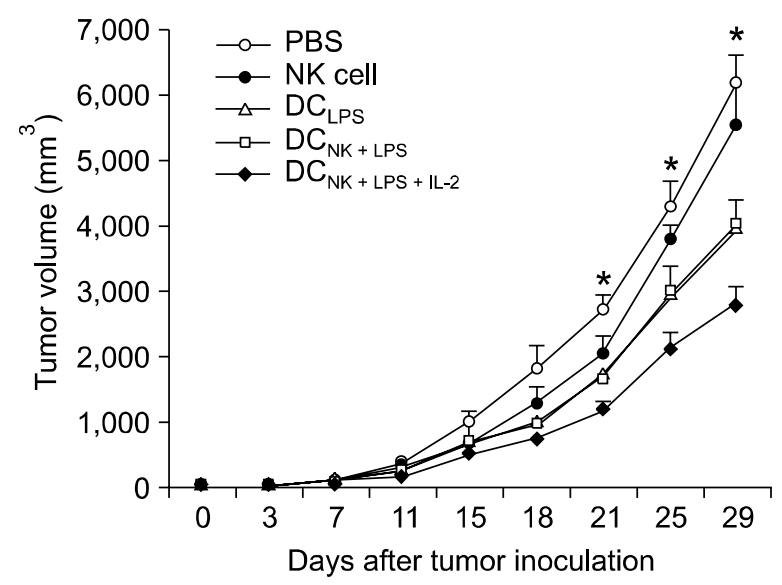

C

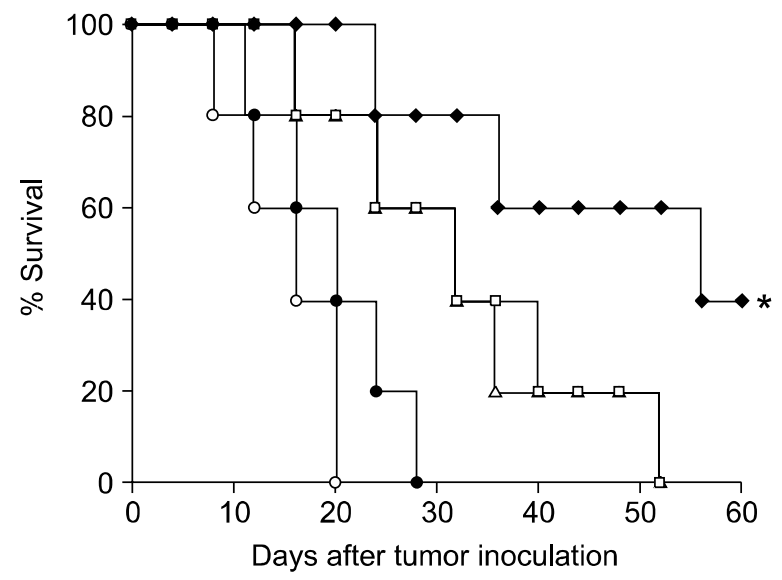

B

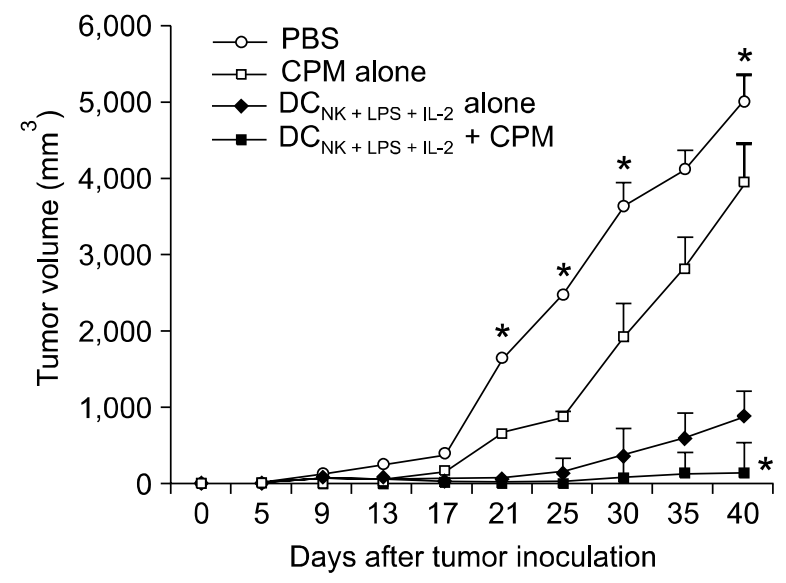

D

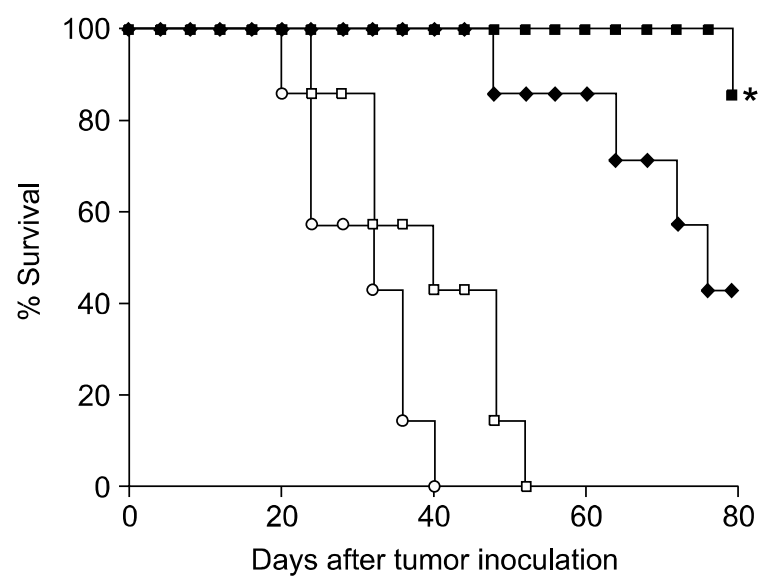

Figure 5. DC vaccinations in mouse colon cancer model. CT-26 cells $\left(5 \times 10^{5} /\right.$ mouse) were injected subcutaneously into the on the right flank of BALB/C mice. (A) Tumor-bearing mice were vaccinated subcutaneously on day $3,7,11$ and 15 with PBS $(\bigcirc)$, NK cells $(\mathbf{\bullet})$, pulsed-DC $C_{L P S}(\Delta)$, pulsed-DC $C_{N K+L P S}$ $(\square)$ and pulsed-DC $C_{N K+L P S+L-2}(\bullet)$. The mice vaccinated with $D C_{L P S}, D C_{N K+L P S}$, and $D C_{N K+L P S+L-2}$ significantly inhibited the tumor growths compared to NK cells and PBS control (*, $P<0.05$ on day 15,21 , and 29$)$. The $\mathrm{DC}_{\mathrm{NK}+\mathrm{LPS}+\mathrm{LL}-2}$ group showed the highest inhibition of tumor growth with a significant prolonged survival rate (C). Each vaccination group was evaluated for survival rate. Experiments consisted of 10 mice per group. (B) Tumor-bearing mice in combination therapy group ( $\mathrm{DC}_{\mathrm{NK}+\mathrm{LPS}+\mathrm{LL}-2}+\mathrm{CPM}$ ) were intraperitoneally treated with $50 \mathrm{mg} / \mathrm{kg}$ of cyclophosphamide (CPM) on day 6 and then vaccinated subcutaneously with DCs on day $9,13,17$ and 21. PBS group $(\bigcirc)$, cyclophosphamide alone $(\square)$, pulsed-DC $C_{N K+L P S+L-2}(\bullet)$, and DC $C_{N K+L P S+H L-2}+C_{C P M}(\square)$ were used for vaccination. Combination therapy of $D C_{N K+L P S+L-2}$ vaccine with low dose of cyclophosphamide resulted in markedly inhibited tumor growth $(*$, $P<0.05$ on days 35 and 40 ) and prolonged survival rate (D). Each vaccination group was evaluated for survival rate every 3-4 days. Experiments consisted of 7 mice per group.

maturated with LPS only ( $\left.\mathrm{DC}_{\mathrm{LPS}}\right)(50.0 \% \pm 1.1 \mathrm{vs}$. $30.3 \% \pm 1.1)$. Addition of IL-2 to $\mathrm{DC}_{\mathrm{NK}+\mathrm{LPS}}$ $\left(D C_{N K+L P S+L L-2}\right)$ had no effect on the efficacy of tumor antigen uptake as compared to $\mathrm{DC}_{\mathrm{NK}+\mathrm{LPS}}$ (Figure 4A).

We examined the CTL responses of BALB/C purified $T$ cells induced by mature DCs pulsed with or without apoptotic CT-26 tumor cells. Spleen T cells stimulated by tumor antigen-pulsed DCs were evaluated by CTL responses against CT26 target cell lines or CT26-pulsed-DCs. The CTLs stimulated by pulsed-DCs produced more IFN- $\gamma$-secreting cells than those stimulated by unpulsed DCs or unprimed T cells $(P<0.05)$. The CTLs that were generated by pulsed-DC $C_{\mathrm{NK}+\mathrm{LPS}+\mathrm{LL}-2}$ produced more IFN- $\gamma$-secreting cells than other CTLs $(P<0.05)$. To evaluate the NK cell-mediated IFN- $\gamma$ production, the NK cell-sensitive YAC-1 cell line was used as target cells for CTLs. These CTLs induced a few number of IFN- $\gamma$-secreting cells against to the YAC-1 cells, indicating CTL-mediated responses rather than NK cell-mediated responses (Figure 4B). 
A

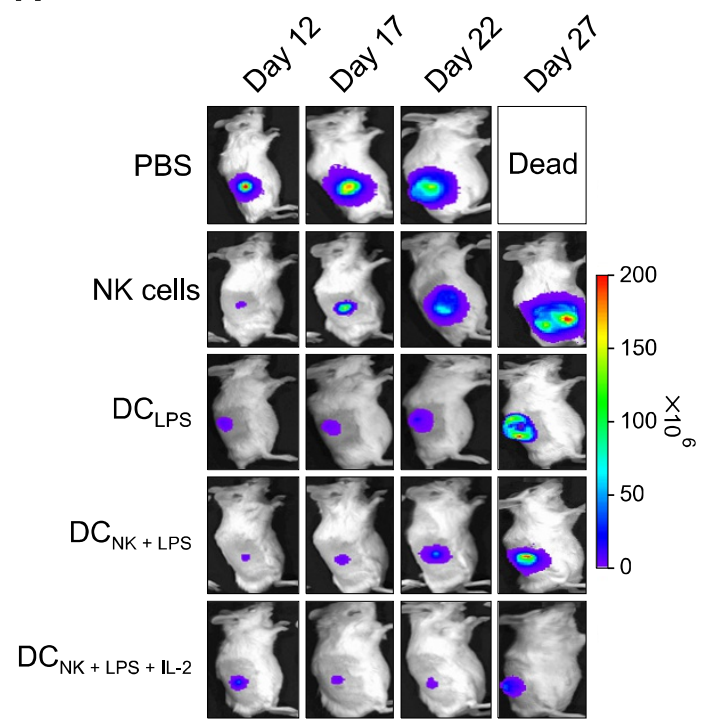

B

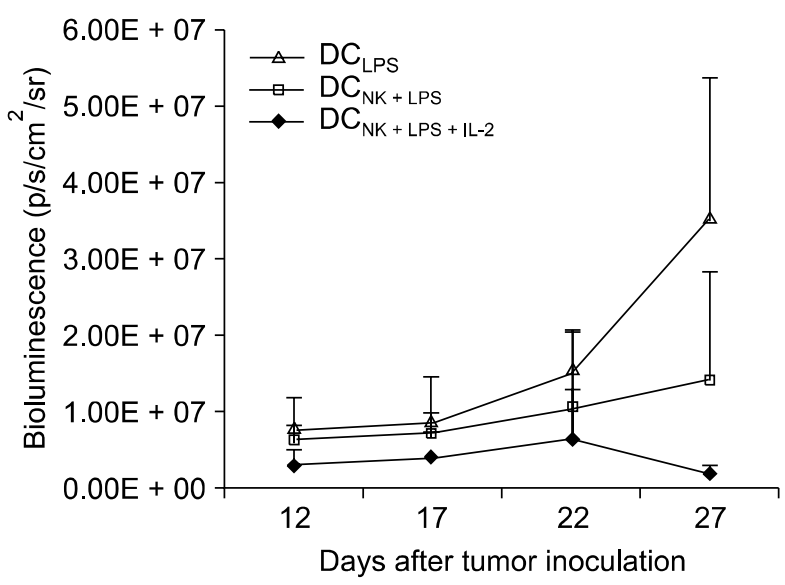

Figure 6. Molecular imaging for antitumor effects of DC vaccinations. Mice were injected with CT26-Fluc and evaluated luciferase signals emitted using the IVIS machine. (A) CT26-Fluc-bearing mice vaccinated with $D C_{L P S}, D C_{N K+L P S}$ and $D C_{N K+L P S+L-2}$ showed a lower bioluminescence signals in tumor sites compared to those vaccinated with the NK cell and PBS control. Representative images of one mouse from the two mice per group are shown. (B) Mice vaccinated with $D C_{N K+L P S+L-2}$ showed the lowest luciferase bioluminescence signals among DC vaccinated groups. The data are shown as the mean of luciferase signals $( \pm$ S.D) from two mice per group.

\section{DC maturation with NK cells in the presence of TLR agonist shows more potent antitumor effect in vivo}

In this study, NK cells with a TLR agonist and IL-2 was the most effective combination for DC maturation to enhance the immune response in vitro. Therefore, we assessed whether these DCs enhanced antitumor immune responses in an animal model. All tumor-bearing mice vaccinated with PBS or NK cells did not inhibit rapid tumor growth that led to sacrifice within three weeks. By contrast, the tumor bearing mice vaccinated with

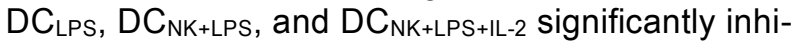
bited tumor growth compared to those with NK cells and PBS $(P<0.05$ on Days 15,21 , and 29 vs. PBS or NK cell). The $\mathrm{DC}_{\mathrm{NK}+\mathrm{LPS}+\mathrm{LL}-2}$ group showed the highest inhibition of tumor growth $(P<$ 0.05 on Days 21 and 29 vs. pulsed-DCLPS or pulsed-DC $C_{N K+L P S}$ ) (Figure $5 \mathrm{~A}$ ) and a significant prolonged survival rate (Figure $5 \mathrm{C}$ ). The survival of mice vaccinated with $D C_{N K+L P S+L L-2}$ was significantly improved as compared to the pulsed-DCLPS or pulsed-DC $\mathrm{NK}_{\mathrm{NK}+\mathrm{LPS}}$ vaccinated groups (35.2 days \pm 2.9 vs. 31.2 days \pm 3.1 and 28.8 days \pm 3.1 ).

To examine the possible immunopotentiation effect to enhance the efficacy of $D_{\text {NK+LPS+LL-2 }}$ vaccine, we assessed combination therapy of DC vaccine with immunomodulatory drug, cyclophosphamide. BALB/c mice were inoculated with CT-26 colon cancer cells on day 0 , followed by treatment with a low-dose of cyclophosphamide on day 6 , and then vaccination with DC vaccine at a 4 day interval from day 9. The treatment with cyclophosphamide alone had little effect on the inhibition of tumor growth (Figure 5B). The vaccination with $\mathrm{DC}_{\mathrm{NK}+\mathrm{LPS}+\mathrm{LL}-2}$ alone showed a significantly inhibition of tumor growth and a significant prolonged of survival as compared to groups treated with PBS control or cyclophosphamide alone $(P<0.05)$. Treatment with a low-dose cyclophosphamide following with $\mathrm{DC}_{\mathrm{NK}+\mathrm{LPS}+\mathrm{LL}-2}$ vaccination resulted in a more marked tumor inhibition markedly inhibited tumor growth, likely as tumor eradicated (Figure 5B) $(P<0.05)$. The survival of mice receiving the combination therapy was significantly prolonged compared to mice receiving the $D C$ vaccine alone (Figure $5 D$ ).

To validate the therapeutic efficacy of the DCs, using a molecular imaging tool, the mice were injected with CT26-Fluc and evaluated luciferase signals emitted from the tumor cells using the IVIS machine. On days $12,17,22$, and 27 , the signals from the CT26-Fluc cells were detected in two mice per group. The CT26-Fluc-bearing mice vaccinated with $\mathrm{DC}_{\mathrm{LPS}}, \mathrm{DC}_{\mathrm{NK}+\mathrm{LPS}}$ and $\mathrm{DC}_{\mathrm{NK}+\mathrm{LPS}+\mathrm{IL}-2}$ showed significant inhibition of tumor growth based on the lower of bioluminescence signals as compared to those vaccinated with the NK cells and PBS control (Figure $6 \mathrm{~A}$ ). Mice vaccinated with $\mathrm{DC}_{\mathrm{NK}+\mathrm{LPS}+\mathrm{IL}-2}$ displayed the lowest luciferase bioluminescence signals among the DC vaccinated groups, indica- 


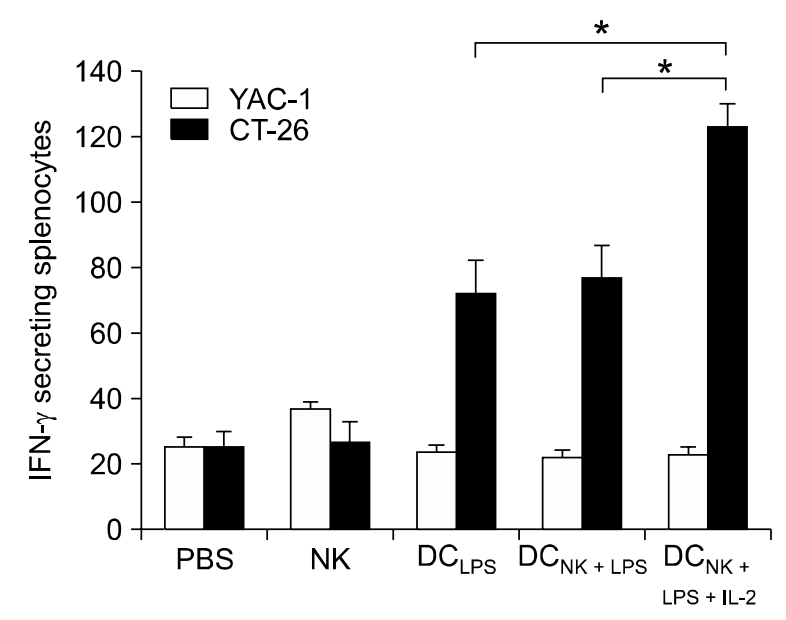

Figure 7. DC vaccine increases the number of IFN- $\gamma$ secreting lymphocytes. The number of IFN- $\gamma$ secreting lymphocytes in spleens of mice treated with PBS, NK cell, DC LPS, $\mathrm{DC}_{\mathrm{NK}+L P S}$ and $\mathrm{DC}_{\mathrm{NK}+\mathrm{LPS}+\mathrm{LL}-2}(n=$ 10) were counted in an IFN- $\gamma$ ELISPOT assay. Vaccination with DCLPS and $\mathrm{DC}_{\mathrm{NK}+\mathrm{LPS}}$ caused an increase in IFN- $\gamma$ secreting lymphocytes, while the vaccination of $D C_{N K+L P S+L-2}$ led to a more dramatic increase in IFN- $\gamma$ secreting lymphocytes $\left.{ }^{*} P<0.05\right)$. The results are expressed as mean numbers of IFN- $\gamma$-secreting cells ( \pm S.D).

ting the highest anti-tumor effects (Figure 6B).

\section{DC maturation with NK cells in the presence of TLR agonist and IL-2 significantly enhances the frequency of tumor-specific CTLs after DC vaccination}

To investigate the anti-tumor effects of cytotoxic $T$ cells produced by DC vaccination in mouse CT-26 colon cancer model, splenocytes from each group of vaccinated mice were prepared for IFN- $\gamma$ ELISPOT assays (Figure 7). NK cell vaccination did not increase the number of IFN- $\gamma$-secreting splenocytes against CT-26 cells, as compared to PBS control, while vaccination with $\mathrm{DC}_{L P S}$ or $D C_{N K+L P S}$ caused a significant increase in IFN- $\gamma$ secreting splenocytes against CT-26 cell. $D C_{N K+L P S+L L-2}$ vaccination dramatically increased the number of IFN- $\gamma$ secreting splenocytes against CT-26 cells $(P<0.05)$. In addition, the cytotoxicity by NK cells, as presented by the number of IFN- $\gamma$ secreting splenocytes against YAC-1 cells, was similar in all vaccination groups. So, these results indicate that the tumor inhibitory effects by DC vaccination in our study are caused by cytotoxic $T$ lymphocytes-mediated responses rather than NK-mediated responses.

\section{Discussion}

The presence of cross-talk between DCs and NK cells is well known in the context of immune responses to infectious agents and tumors (Ferlazzo et al., 2002; Gerosa et al., 2002; Moretta, 2002; Piccioli et al., 2002). Previous studies have shown that NK cells activated with TLR ligands result in the increased production of IFN- $\gamma$ (Chalifour et al., 2004; Schmidt et al., 2004; Sivori et al., 2004; Hart et al., 2005; Lauzon et al., 2006), which may be a crucial factor for enhancing DC maturation in vivo or in vitro (Granucci et al., 2004). In addition, DCs have been shown to secrete IL-12, which is important for IFN- $\gamma$ production by NK cells in murine viral infection (Orange et al., 1996). Here, we demonstrated that mouse BM-derived DCs could be potentially matured with NK cells in the presence of LPS. Reciprocally, NK cells might be activated by DCs in the presence of LPS. Compared with other DCs in this study, $D C_{N K+L P S+L L-2}$ group showed higher expression of several costimulatory molecules and 1.5-2 times greater secretion of IL-12. Nanogram quantities of IL-12 were produced by these DCs, and these concentrations of IL-12 were sufficient to increase IFN- $\gamma$ production by NK cells. Our results suggest one possible model in which LPS directly activates both NK cells and DCs, and the interaction between these two cell types during stimulation further enhances their activation.

The goal of immunotherapy is to induce or up-regulate $T$ cell-mediated tumor-specific immune responses. Although high T cells stimulatory capacity and tumor antigen uptake were observed in the $D C_{L P S}$ group, the DC $C_{N K+L P S+L L-2}$ group induced much more effective and functional $\mathrm{T}$ cell responses, based on the allogeneic responses and tumor-specific CTL responses, which were manifested by their superior induction of $\mathrm{T}$ cell proliferation, high ability to take up tumor material and higher induction of IFN- $\gamma$-secreting cells. The data from this study suggest that fully mature DCs are genereated with NK cells in the presence of TLR agonist and IL-2 and could be potentially useful for immunotherapy against cancer.

The suppressive effects of tumor cells during DC generation have been explained previously by the ability of the tumor microenvironment to suppress DC differentiation (Savill et al., 2002; Yu et al., 2007). The suppression is due to the activation of STAT3 and the production of immunosuppressive factors, such as vascular endothelial growth factor, $\mathrm{IL}-10$, and $\mathrm{IL}-6$ in the tumor microenvironment. Although we did not observe significant inhibitory effects of tumor cells during DC maturation in DC phenotype and IL-12p40 production, IL-12p70 production was significantly declined. Therefore, the inhibitory effects of tumor cells may play some 
role in DC differentiation. Further studies to provide evidence for this process are needed. Prior studies have shown that STAT3 blocking or inhibition of MAPK activity enhance the immune-mediated antitumor effects of DCs (Nefedova et al., 2005; Wang et al., 2006).

A crucial factor for the successful generation of the potent DCs in our study was the ratio of the DCs:NK cells. The interaction of immature DCs with activated NK cells results in either maturation or cell death. The determination between death and maturation when DCs were exposed to activated NK cells was mainly related with the ratio of the DCs:NK cells (Gerosa et al., 2002; Piccioli et al., 2002). When DC:NK cell ratios were >1:5, inhibition of DC function was the dominant feature of the DC interaction with activated NK cells due to direct killing of immature DCs (Piccioli et al., 2002). Indeed, both DC maturation and cytokine production (TNF- $\alpha$ and IL-12) observed at an equal ratio $(\leq 1: 2)$ were abrogated when the number of NK cells were increased (Piccioli et al., 2002). Similarly, our results indicated that the optimal ratio was $1: 1$ to $1: 2$, which showed higher expression of several molecules and higher production of cytokines in comparison to other ratios.

Recently, several DC-based vaccines using known tumor antigens in mouse colon cancer models have been reported (Jack et al., 2007; Yamaguchi et al., 2007; Shortman et al., 2009). In our study, tumor apoptotic cells were used to load on DCs to generate CTLs in tumor bearing mice.

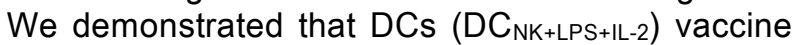
effectively enhanced antitumor effects in mouse colon cancer model. IFN- $\gamma$ ELISPOT assays revealed that tumor antigen-pulsed DCs resulted in the superior induction of tumor-specific CTLs. These DC vaccines induced antitumor responses against CT26 colon carcinoma and inhibited tumor growth in the tumor-bearing mice. In addition, IFN- $\gamma$ ELISPOT assay with splenocytes from each group of vaccinated mice reveal that our DC vaccine resulted in the strong tumor specific CTL-mediated responses against CT-26 tumor cells rather than NK cell-mediated response. Therefore, $D C_{N K+L P S+L L-2}$ could be used as an excellent DC vaccine against colon cancer.

IL-2-activated human NK cells can trigger maturation of immature DCs by up-regulation of co-stimulatory molecule, CD86, resulting in enhancement of T cell stimulatory capacity of DCs (Gerosa et al., 2002). However, IL-2-activated NK cells did not induce more maturation of DCs than LPS-activated NK cells in our study (data not shown). In addition, IL-2 does not act directly on DC-inducing maturation (data not shown). TLR is expressed in both NK cells and DCs, and TLR ligands play a role in the activation of NK cells as well as maturation of iDCs. Interestingly, our data showed that NK cells were efficiently activated by DCs in the presence of LPS and IL-2. Consistently, the effects of NK cells in generation of potent DCs were optimized in the presence of LPS and IL-2. Therefore, we suggest the activation events occurring in co-culture of NK cells and DCs in the presence of LPS and IL-2 as followed. First, NK cells start to activate by IL-2 and then by LPS or both, whereas DCs start to activate by LPS to release abundant IL-12. Second, NK cells exposed to IL-12 are further activated and can kill iDCs, thus favoring the survival of mature DCs. Third, the activated NK cells produce TNF- $\alpha$ (data not shown) to promote further maturation of DCs and production of IFN- $\gamma$, which increase the production of IL-12p70 and induce Th1 immune responses. Finally, the inhibitory effects of $D_{\mathrm{NK}+L P S+I L-2}$ vaccines against tumors were dramatically enhanced through this positive feedback loop.

In animal colon cancer models, DC-based vaccines have been reported to induce significant antitumor responses (Jack et al., 2007; Yamaguchi et al., 2007). However, the methods to improve the efficacy of DC-based vaccines should be investigated to enhance the effect of vaccination. In this study, we investigated the combination effect of low-dose chemotherapy and potent $D_{\mathrm{NK}+\mathrm{LPS}+\mathrm{IL}-2}$ vaccines because cyclophosphamide is frequently used to enhance or augment the antitumor effects in the field of immunotherapy against cancer (North, 1982; Ghiringhelli et al., 2004; Mihalyo et al., 2004; Young et al., 2006). The possible effect of cyclophosphamide to enhance the antitumor efficacy of DC vaccine may be due to the increasing proportion of IFN- $\gamma$ secreting lymphocytes in combination with the suppressing proportion of $\mathrm{CD}^{+} \mathrm{CD}^{2} 5^{+} \mathrm{FoxP}^{+}$regulatory $\mathrm{T}$ (Treg) cells in tumor-bearing mice (Liu et al., 2007). The results of a clinical trial using allogeneic DC vaccine combined with low-dose cyclophosphamide has revealed that the combination therapy could induce stronger antitumor response compared with DC vaccine alone (Holtl et al., 2005). Consistently, our results showed that a single administration of low-dose cyclophosphamide before the first DC vaccination augmented the antitumor effects of DC vaccine to eradicate tumor completely and consequently prolonged the survival of vaccinated mice.

In conclusion, the results of our study suggest that potent DCs can be generated by NK cells in the presence of TLR agonist and IL-2, and used to effectively induce tumor specific CTLs that exert an anti-tumor immune response. 


\section{Methods}

\section{Mice and tumor cell lines}

Six- to eight-week-old female BALB/c $\left(\mathrm{H}-2^{\mathrm{d}}\right)$ mice were purchased from Orient Bio (Iksan, South Korea), and were maintained in specific pathogen-free conditions. All animal care, experiments and euthanasia were performed in accordance with protocols approved by the Chonnam National University Animal Research Committee. The murine BALB/c-derived colon carcinoma cell lines, CT26 and CT26-Fluc (CT26 carrying Fluc gene), were kindly provided by Dr. Min JJ (Chonnam National University, Korea) and YAC-1 was purchased from American Type Culture Collection (Rockville, MD). The CD40 ligand (CD40L)-transfected J558 cell line was kindly provided by Dr. Kalinski (University of Pittsburgh). All cell lines were maintained in RPMI-1640 medium (Gibco-BRL, Grand Island, NY) supplemented with 10\% FBS (Gibco-BRL) and $1 \%$ penicillin/streptomycin.

\section{Generation of BM-derived DCs}

$B A L B / c$ BM-derived immature DCs were generated as described previously (Lutz et al., 1999). Briefly, BM was harvested from the femurs and tibiae of mice and cultured in RPMI-1640 (Gibco-BRL) supplemented with 10\% FBS (Gibco-BRL) and 1\% penicillin/streptomycin, in the presence of $5 \mathrm{ng} / \mathrm{ml}$ recombinant murine $(\mathrm{rm}) \mathrm{GM}-\mathrm{CSF}$ (R\&D Systems, Minneapolis, MN) and $5 \mathrm{ng} / \mathrm{ml} \mathrm{rmlL-4}$ (R\&D Systems). On day 3, fresh complete medium containing cytokines was added to the adherent cells. On day 7 of culture, non-adherent and loosely adherent cells were harvested and used for the experiments as immature DCs.

\section{NK cell purification}

Mouse NK cells were positively isolated from splenocytes of $B A L B / c$ mice. Briefly, the spleen was removed under sterile conditions; tissue was dissociated and then filtered through a $40-\mu \mathrm{m}$ nylon cell strainer (BD Biosciences-Labware). Erythrocytes were removed using $0.83 \%(\mathrm{w} / \mathrm{v}) \mathrm{NH}_{4} \mathrm{Cl}$ red blood cells lysis buffer. NK cells were isolated by positive selection using the magnetic activated cell sorter (MACS; Miltenyi Biotec, Auburn, CA) system. The purity of NK cells was $>96 \%$ for CD49b (DX5).

\section{Maturation of DCs}

Immature DCs were cultured at $1 \times 10^{6}$ cells/well in 24-well plates (BD Biosciences-Labware). For DC maturation using DC-NK interaction, immature DCs $\left(1 \times 10^{6}\right.$ cells) were directly co-cultured with purified NK cells $(2 \times$ $10^{6}$ cells) in the presence of $1 \mu \mathrm{g} / \mathrm{ml}$ lipopolysaccharides (LPS) from Escherichia coli (Sigma-Aldrich, St. Louis, MO) and/or $5 \mathrm{ng} / \mathrm{ml} \mathrm{rmlL}-2$ (R\&D Systems) for 2 days in the following three subgroups: LPS alone (DC $\left.C_{L P S}\right)$, NK cells in the presence of LPS (DC $\mathrm{NK}_{\mathrm{LPS}}$ ) or NK cells in the presence of LPS and IL-2 (DC $\left.\mathrm{NK}_{\mathrm{N}+\mathrm{LPS}+\mathrm{LL}-2}\right)$. Before use for analysis, mature DCs were harvested and washed three times to remove all extra reagents.

\section{Phenotypic analysis of DCs}

Fluorescence-activated cell sorting (FACS) analysis was performed using monoclonal antibodies (mAb) against murine MHC class II (I-A $\left.{ }^{\mathrm{d}}\right)-\mathrm{PE}, \mathrm{CD} 40-\mathrm{PE}, \mathrm{CD} 80-\mathrm{FITC}$ and CD86-PE (PharMingen, San Diego, CA). Isotype matched controls were run in parallel. Cell debris was eliminated by forward and side scatter gating. The samples were acquired on a FACSAria cell sorter (Becton Dickinson, San Jose, CA) and the data were analyzed with WinMDI Version 2.9 (Bio-Soft Net).

\section{Mouse IFN- $\gamma$, IL-12p40 and IL-12p70 production}

Measurements of mouse IFN- $\gamma, \mathrm{IL}-12 \mathrm{p} 40$ and IL-12p70 cytokines during maturation of DCs were determined by BD OptEIA ${ }^{\mathrm{TM}}$ ELISA Set (BD Bioscience). In addition, mature DCs were plated in 96-well plates at $2 \times 10^{4}$ cells/well and stimulated with CD40L-transfected J558 cells $\left(5 \times 10^{4}\right.$ cells/well), which mimic the interaction with CD40L-expressing Th cells, for $24 \mathrm{~h}$ to secrete IL-12p70 upon the follow-up activation.

\section{Generation of apoptotic CT26 cells for loading on DCs}

Apoptotic CT26 cells were induced by high-dose UVB irradiation $\left(120 \mathrm{~mJ} / \mathrm{cm}^{2}\right)$ (International light, Newburyport, MA) followed by overnight culture in RPMI-1640. The apoptotic irradiated-CT26 cells were confirmed using Annexin V-FITC Apoptosis Detection Kit (BD Bioscience) and pulsed with immature DCs at $6 \mathrm{~h}$ after maturation at a ratio of 2:1 (DCs: apoptotic cells).

To measure tumor antigen uptake by DCs, CD11c ${ }^{+}$ immature DCs were isolated by MACS separation (Miltenyi Biotec). CT26 cells were stained with PKH26 (Sigma-Aldrich) before UVB irradiation. After maturation, tumor-loaded, mature $\mathrm{CD} 11 \mathrm{c}^{+} / \mathrm{H}-2 \mathrm{k}^{+}$or $\mathrm{CD} 11 \mathrm{c}^{+} / \mathrm{CD} 80^{+} \mathrm{DCs}$ were analyzed by flow cytometry for the expression of PKH26.

\section{Allogeneic mixed lymphocyte reaction}

Allogeneic mouse $T$ cells were positively isolated from splenocytes of B16F10 mice using positive selection with a MACS system (Miltenyi Biotec). The responder T cells (2 $\times 10^{4} /$ well $)$ were co-cultured with graded doses $\left(3 \times 10^{2}\right.$ to $2 \times 10^{4}$ ) of irradiated $\mathrm{DC}_{\mathrm{LPS}}, \mathrm{DC}_{\mathrm{NK}+\mathrm{LPS}}$, and $\mathrm{DC}_{\mathrm{NK}+\mathrm{LPS}+\mathrm{IL}-2 \text {. }}$ On day 5 , the cultured cells were pulsed with $1 \mu \mathrm{Ci}$ of $\left[{ }^{3} \mathrm{H}\right]$-methylthymidine per well during the last $18 \mathrm{~h}$ of culture, and then analyzed in a liquid scintillation counter (Beckman, Fullerton, CA). The results were expressed as the mean cpm $\pm S D$ of triplicate cultures. Unprimed T cells were used as a control.

\section{In vitro CTL generation and IFN- $\gamma$ ELISPOT Assay}

Autologous mouse $\mathrm{T}$ cells $\left(1 \times 10^{6}\right.$ cells $)$ isolated from splenocytes using MACS system (Miltenyi Biotec) were co-cultured as effector cells at a ratio of $5: 1$ with either tumor-pulsed or unpulsed DC $C_{L P S}, D_{N K+L P S}$ or $D_{N K+L P S+I L-2}$ $\left(2 \times 10^{5}\right.$ cells) in $2 \mathrm{ml}$ of medium (RPMl 1640: AIM-V = 1:1) containing $10 \%$ FBS (Gibco-BRL) and $1 \%$ penicillin-strep- 
tomycin (Gibco-BRL) supplemented with $20 \mathrm{U} / \mathrm{ml} \mathrm{rmlL-2}$ (R\&D Systems). The medium was replenished with cytokines every 3 days. On day 7, the CTL lines were harvested and used for ELISPOT assay using a mouse IFN- $\gamma$ ELISPOT Set (BD Bioscience). The frequency of antigen-specific CTL lines was analyzed using the CT26 tumor cell line and mature DCs pulsed with CT26 apoptotic tumor cells as targets cells. The spots were counted with an ImmunoSpot Reader (Cellular Technology Ltd, Ohio). The data were presented as the mean \pm SD of IFN- $\gamma$ secreting cell per well of triplicate samples. CTL cells alone were used as the control.

\section{In vivo animal vaccination}

In original schedule to investigate the efficacy of our generated potent DCs, five vaccination groups were used: (1) pulsed-DC $C_{L P S}$, (2) pulsed-DC $C_{N K+L P S}$, (3) pulsed$\mathrm{DC}_{\mathrm{NK}+\mathrm{LPS}+\mathrm{LL}-2,}$ (4) NK cells and (5) PBS control. Each vaccine $\left(1 \times 10^{6}\right.$ cells/mouse $)$ was administered subcutaneously at the left flank in a volume of $0.1 \mathrm{ml}$ of PBS at a 4 day interval on days 3, 7, 11 and 15 after subcutaneous inoculation of CT26 tumor cells $\left(5 \times 10^{5}\right.$ cells/mouse) on the right flank of BALB/c mice in a volume of $0.1 \mathrm{ml}$ on day 0 .

For combine with low-dose chemotherapy, four vaccination groups were used: (1) cyclophosphamide alone, (2) pulsed-DC $\mathrm{NK}_{\mathrm{LPS}+\mathrm{LL}-2}$ alone, (3) pulsed$\mathrm{DC}_{\mathrm{NK}+\mathrm{LPS}+\mathrm{LL}-2}$ combination with cyclophosphamide and (4) PBS control. Firstly, to determine the optimal low-doses of cyclophosphamide, a dose range between 50 to $400 \mathrm{mg} / \mathrm{kg}$ was tested. The dose of $50 \mathrm{mg} / \mathrm{kg}$ was showed to low cytotoxic to CT26 tumor cells compared with other doses. CT26 tumor cells $\left(5 \times 10^{5}\right.$ cells/mouse $)$ were inoculated on the right flank of BALB/c mice in a volume of $0.1 \mathrm{ml}$ on day 0 . A single low-dose of cyclophosphamide $(50 \mathrm{mg} / \mathrm{kg}$ ) was injected intraperitoneally on day 6 preceding the first DCs vaccination in indicated mice. DC vaccine $\left(1 \times 10^{6}\right.$ cells/mouse) was administered subcutaneously at a 4 day interval on days $9,13,17$ and 21 .

To assess the anti-tumor efficacy of vaccinated mice, three perpendicular dimensions (length, width, and height) of each tumor were measured individually every 3-4 days with a vernier caliper, and the tumor volume was calculated using the formula for the standard volume of an ellipsoid as follows: $V=4 / 3 \pi$ (lengh*width*height/8). To assess the survival prolongation of vaccinated mice, the mice were euthanized when the tumor volume reached $2.5 \mathrm{~cm}$ in diameter, which was considered as a death due to the size of tumor.

For in vivo molecular imaging, 2 mice of each group in original schedule were inoculated with CT26-Fluc cells. Imaging was performed 12 days after tumor inoculation, when the bioluminescent signal from CT26-Fluc could be detected. The bioluminescence expression of CT26-Fluc was detected by intraperitoneal injection of $100 \mu \mathrm{l}(7.5$ $\mathrm{mg} / \mathrm{mL}$ ) of D-luciferin (Caliper, Hopkinton, MA) using the IVIS100 system (Caliper) equipped with a cooled charged couple detector camera. The results were analyzed using the Living Image software v. 2.25 (Caliper). A region of interest (ROI) was selected manually over the signal intensity. The area of the ROI was kept constant, and the intensity was recorded as maximum within a ROI.

\section{Tumor antigen specific CTLs of vaccinated mice}

Splenocytes $\left(1 \times 10^{6}\right.$ cells) isolated from vaccinated mice on 7 days after the last immunization (day 22) were added to 24-well plates and, then, restimulated with irradiated CT-26 cells $\left(5 \times 10^{5}\right.$ cells $)$ for 5 days in RPMI-1640 (Gibco-BRL) supplemented with 10\% FBS (Gibco-BRL) and $1 \%$ penicillin/streptomycin. After restimulation, the splenocytes were collected and tested for detection of the tumor antigen-specific cytotoxic $\mathrm{T}$ lymphocytes using a mouse IFN- $\gamma$ ELISPOT Set (BD Bioscience). The CT-26 tumor cell line and NK-sensitive YAC-1 cell line were used as targets cells.

\section{Statistical analysis}

The Mann-Whitney $U$ test was performed for statistical significance of nonparametric differences among groups. Survival of the vaccinated mice was analyzed using Kaplan-Meier method with SPSS 13.0 program software and compared using log-rank test. $P$ values $<0.05$ were considered statistically significant.

\section{Supplemental data}

Supplemental Data include two figures and can be found with this article online at http://e-emm.or.kr/article/article_ files/SP-42-6-01.pdf.

\section{Acknowledgements}

This study was financially supported by a grant of the Korea Healthcare technology R\&D Project (A080489), Ministry of Health \& Welfare, Republic of Korea.

\section{References}

Akira S, Hemmi H. Recognition of pathogen-associated molecular patterns by TLR family. Immunol Lett 2003;85: 85-95

Andrews DM, Scalzo AA, Yokoyama WM, Smyth MJ, Degli-Esposti MA. Functional interactions between dendritic cells and NK cells during viral infection. Nat Immunol 2003;4:175-81

Berd D, Maguire HCJ, Mastrangelo MJ. Potentiation of human cell-mediated and humoral immunity by low-dose cyclophosphamide. Cancer Res 1984;44:5439-43

Chalifour A, Jeannin P, Gauchat JF, Blaecke A, Malissard M, N'Guyen T, Thieblemont N, Delneste Y. Direct bacterial protein PAMP recognition by human NK cells involves TLRs and triggers alpha-defensin production. Blood 2004;104: 1778-83

Cooper MA, Fehniger TA, Fuchs A, Colonna M, Caligiuri MA. NK cell and DC interactions. Trends Immunol 2004;25: 47-52

Cranmer LD, Trevor KT, Hersh EM. Clinical applications of dendritic cell vaccination in the treatment of cancer. Cancer 
Immunol Immunother 2004:53:275-306

Ferlazzo G, Tsang ML, Moretta L, Melioli G, Steinman RM, Munz $C$. Human dendritic cells activate resting natural killer (NK) cells and are recognized via the NKp30 receptor by activated NK cells. J Exp Med 2002;195:343-51

Gerosa F, Baldani-Guerra B, Nisii C, Marchesini V, Carra G, Trinchieri G. Reciprocal activating interaction between natural killer cells and dendritic cells. J Exp Med 2002; 195:327-33

Ghiringhelli F, Larmonier N, Schmitt E, Parcellier A, Cathelin D, Garrido C, Chauffert B, Solary E, Bonnotte B, Martin F. CD4+CD25+ regulatory $T$ cells suppress tumor immunity but are sensitive to cyclophosphamide which allows immunotherapy of established tumors to be curative. Eur J Immunol 2004;34:336-44

Granucci F, Zanoni I, Pavelka N, Van Dommelen SL, Andoniou CE, Belardelli F, Degli Esposti MA, Ricciardi-Castagnoli P. A contribution of mouse dendritic cell-derived IL-2 for NK cell activation. J Exp Med 2004;200:287-95

Hart OM, Athie-Morales V, O'Connor GM, Gardiner CM. TLR7/8-mediated activation of human NK cells results in accessory cell-dependent IFN-gamma production. J Immunol 2005;175:1636-42

Holtl L, Ramoner R, Zelle-Rieser C, Gander H, Putz T, Papesh C, Nussbaumer W, Falkensammer C, Bartsch G, Thurnher M. Allogeneic dendritic cell vaccination against metastatic renal cell carcinoma with or without cyclophosphamide. Cancer Immunol Immunother 2005;54:663-70

Jack AM, Aydin N, Montenegro G, Alam K, Wallack M. A novel dendritic cell-based cancer vaccine produces promising results in a syngenic CC-36 murine colon adenocarcinoma model. J Surg Res 2007;139:164-9

Kalinski P, Giermasz A, Nakamura Y, Basse P, Storkus WJ, Kirkwood JM, Mailliard RB. Helper role of NK cells during the induction of anticancer responses by dendritic cells. Mol Immunol 2005;42:535-9

Lauzon NM, Mian F, MacKenzie R, Ashkar AA. The direct effects of Toll-like receptor ligands on human NK cell cytokine production and cytotoxicity. Cell Immunol 2006;241:102-12

Liu JY, Wu Y, Zhang XS, Yang JL, Li HL, Mao YQ, Wang Y, Cheng $X$, Li YQ, Xia JC, Masucci M, Zeng YX. Single administration of low dose cyclophosphamide augments the antitumor effect of dendritic cell vaccine. Cancer Immunol Immunother 2007;56:1597-604

Lutz MB, Kukutsch N, Ogilvie AL, Rossner S, Koch F, Romani $\mathrm{N}$, Schuler $\mathrm{G}$. An advanced culture method for generating large quantities of highly pure dendritic cells from mouse bone marrow. J Immunol Methods 1999;223:77-92

Mailliard RB, Son YI, Redlinger R, Coates PT, Giermasz A, Morel PA, Storkus WJ, Kalinski P. Dendritic cells mediate NK cell help for Th1 and CTL responses: two-signal requirement for the induction of NK cell helper function. J Immunol 2003;171:2366-73

Matar P, Rozados VR, Gonzalez AD, Dlugovitzky DG, Bonfil RD, Scharovsky OG. Mechanism of antimetastatic immunopotentiation by low-dose cyclophosphamide. Eur J

\section{Cancer 2000;36:1060-6}

Matar P, Rozados VR, Gervasoni SI, Scharovsky GO. Th2/Th1 switch induced by a single low dose of cyclophosphamide in a rat metastatic lymphoma model. Cancer Immunol Immunother 2002;50:588-96

Mihalyo MA, Doody AD, McAleer JP, Nowak EC, Long M, Yang $\mathrm{Y}$, Adler AJ. In vivo cyclophosphamide and IL-2 treatment impedes self-antigen-induced effector CD4 cell tolerization: implications for adoptive immunotherapy. $J$ Immunol 2004;172:5338-45

Moretta A. Natural killer cells and dendritic cells: rendezvous in abused tissues. Nat Rev Immunol 2002;2:957-64

Nefedova Y, Nagaraj S, Rosenbauer A, Muro-Cacho C, Sebti $\mathrm{SM}, \mathrm{Gabrilovich}$ DI. Regulation of dendritic cell differentiation and antitumor immune response in cancer by pharmacologic-selective inhibition of the janus-activated kinase $2 /$ signal transducers and activators of transcription 3 pathway. Cancer Res 2005;65:9525-35

North RJ. Cyclophosphamide-facilitated adoptive immunotherapy of an established tumor depends on elimination of tumor-induced suppressor T cells. J Exp Med 1982;155: 1063-74

Orange JS, Biron CA. An absolute and restricted requirement for IL-12 in natural killer cell IFN-gamma production and antiviral defense. Studies of natural killer and $\mathrm{T}$ cell responses in contrasting viral infections. J Immunol 1996; 156:1138-42

Osada T, Nagawa H, Kitayama J, Tsuno NH, Ishihara S, Takamizawa M, Shibata Y. Peripheral blood dendritic cells, but not monocyte-derived dendritic cells, can augment human NK cell function. Cell Immunol 2001;213:14-23

Piccioli D, Sbrana S, Melandri E, Valiante NM. Contact-dependent stimulation and inhibition of dendritic cells by natural killer cells. J Exp Med 2002;195:335-41

Proietti E, Greco G, Garrone B, Baccarini S, Mauri C, Venditti M, Carlei D, Belardelli F. Importance of cyclophosphamide-induced bystander effect on T cells for a successful tumor eradication in response to adoptive immunotherapy in mice. J Clin Invest 1998;101:429-41

Ridgway D. The first 1000 dendritic cell vaccinees. Cancer Invest 2003;21:873-86

Savill J, Dransfield I, Gregory C, Haslett C. A blast from the past: clearance of apoptotic cells regulates immune responses. Nat Rev Immunol 2002;2:965-75

Schmidt KN, Leung B, Kwong M, Zarember KA, Satyal S, Navas TA, Wang F, Godowski PJ. APC-independent activation of NK cells by the Toll-like receptor 3 agonist double-stranded RNA. J Immunol 2004;172:138-43

Schuurhuis DH, Fu N, Ossendorp F, Melief CJ. Ins and outs of dendritic cells. Int Arch Allergy Immunol 2006;140:53-72

Shortman K, Lahoud MH, Caminschi I. Improving vaccines by targeting antigens to dendritic cells. Exp Mol Med 2009;41:61-6

Sivori S, Falco M, Della Chiesa M, Carlomagno S, Vitale M, Moretta L, Moretta A. CpG and double-stranded RNA trigger 
human NK cells by Toll-like receptors: induction of cytokine release and cytotoxicity against tumors and dendritic cells. Proc Natl Acad Sci USA 2004;101:10116-21

Wang S, Yang J, Qian J, Wezeman M, Kwak LW, Yi Q. Tumor evasion of the immune system: inhibiting p38 MAPK signaling restores the function of dendritic cells in multiple myeloma. Blood 2006;107:2432-9

Yamaguchi S, Tatsumi T, Takehara T, Sakamori R, Uemura A, Mizushima T, Ohkawa K, Storkus WJ, Hayashi N. Immunotherapy of murine colon cancer using receptor tyrosine kinase EphA2-derived peptide-pulsed dendritic cell vaccines. Cancer 2007;110:1469-77

Young SD, Whissell M, Noble JC, Cano PO, Lopez PG, Germond CJ. Phase II clinical trial results involving treatment with low-dose daily oral cyclophosphamide, weekly vinblastine, and rofecoxib in patients with advanced solid tumors. Clin Cancer Res 2006;12:3092-8.

Yu H, Kortylewski M, Pardoll D. Crosstalk between cancer and immune cells: role of STAT3 in the tumour microenvironment. Nat Rev Immunol 2007;7:41-51 